in vivo $34: 557-568(2020)$

doi: $10.21873 /$ invivo. 11808

\title{
Implantation of an Injectable Bone Substitute Material Enables Integration Following the Principles of Guided Bone Regeneration
}

\author{
MIKE BARBECK ${ }^{1,2^{*}}$, OLE JUNG ${ }^{1,3^{*}}$, RALF SMEETS $^{1}$, MARTIN GOSAU $^{1}$, REINER SCHNETTLER $^{1}$, \\ PATRICK RIDER ${ }^{2}$, ALIREZA HOUSHMAND $^{1 *}$ and TADAS KORZINSKAS ${ }^{1 *}$ \\ ${ }^{1}$ University Hospital Hamburg-Eppendorf, Department of Oral and Maxillofacial Surgery, Hamburg, Germany; \\ ${ }^{2}$ BerlinAnalytix GmbH, Berlin, Germany; \\ ${ }^{3}$ Clinic and Policlinic for Dermatology and Venereology, University Medical Center Rostock, Rostock, Germany
}

\begin{abstract}
Background/Aim: The present study investigates the in vivo tissue reaction and the integration behavior of an injectable bone substitute material (IBS) composed of a waterbased gel combined with nano hydroxyapatite particles and biphasic calcium phosphate granules. The results of the IBS were compared to biphasic bone substitute granules (BBSM) of the same chemical composition. Materials and Methods: The subcutaneous implantation model in 40 female 5-week-old CD1 mice up to 60 days after implantation was used for conduction of the in vivo experiments. Moreover, established histological, histopathological and histomorphometrical methods were applied. Results: The results showed that the IBS was gradually invaded by cells and complex tissue elements. Thus, the implant bed could be distinguished in two areas, i.e. an outer and inner region. While the outer region started to interact with the periimplant tissue by evoking multinucleated giant cells and at earlier time points by undergoing a continuous high vascularization, the inner part was free of peri-implant cells for at least 30 days, starting to undergo a similar tissue reaction at a later time point. The bone substitute granules allowed for a fast tissue influx between the interspaces of the granules starting at day 10. While the vessel density did not differ in both groups up to the end of the study, the amount of vascularization was significantly higher over the entire observation period in the
\end{abstract}

This article is freely accessible online.

*These Authors contributed equally to this study.

Correspondence to: Mike Barbeck, Martinistrasse 52, 20246 Hamburg, Germany. Tel: +49 17681022467, e-mail: mike.barbeck@icloud.com

Key Words: Injectable bone substitute (IBS), biphasic bone substitute (BBSM), integration, vascularization, multinucleated giant cells, bone regeneration, guided bone regeneration (GBR).
BBSM group. Moreover, the amount of biomaterial-associated multinucleated giant cells (BMGCs) was significantly higher in the IBS group in the period of between 15 to 30 days after implantation, while comparable BMGC numbers were found in both groups towards the end of the study. Conclusion: IBS can build a barrier-like structure that is able to control the soft tissue influx into the central regions of the implantation bed, which could not be observed in other bone substitute granules of the same chemical composition. This directed integration behavior is assumed to be in accordance with the concept of Guided Bone Regeneration (GBR). Furthermore, BMGCs can significantly influence the process of angiogenesis within an implant bed of a biomaterial but not the maturity of blood vessels.

Alloplastic bone substitutes, especially hydroxyapatite (HA), alpha- and beta- tricalcium phosphate ( $\alpha$-TCP and $\beta$-TCP) and biphasic calcium phosphate ceramics are viable alternatives to autogenous, allogeneic and xenogeneic bone grafts in surgical bone augmentation and replacement (1). Even though they lack some of the qualities of autografts, allografts and xenografts such as osteogenesis and osteoinduction, alloplastic bone substitutes are osteoconductive (2-6), readily available in different easy-to-use forms (7-9), and pose no risk of disease transmission or morbidities associated with bone graft harvesting (10-12). It has been shown that these biomaterials are mainly degraded by the process of phagocytosis, which is affected by the chemical composition and physical characteristics of a biomaterial. These properties determine the cellular reactions within the host tissue, including different numbers of phagocytes such as macrophages and so-called biomaterial-associated multinucleated giant cells (BMGCs) (1, 10, 13-20). Even biphasic bone substitute materials (BBSM) composed of mixtures of hydroxyapatite (HA) and betatricalcium phosphate ( $\beta$-TCP) have shown to be degraded in a balanced way. For BBSMs, the tissue reaction is formed by the individual reactions towards each of the material 
compounds. Therefore, aspects such as biodegradation is based on the activity of phagocytes such as macrophages and BMGCs towards the individual compounds $(10,12,17,20$ 26). Hence, BBSMs initially induce an inflammatory tissue reaction similar to that of a pure $\beta$-TCP material, resulting in a high number of BMGCs and a high degradation rate, at later stages this is followed by a slower degradation rate correlated with lower BMGC numbers at a later, which can be compared to pure HA (17).

Moreover, underlying factors like the implant bed vascularization have shown to be important determinants of the bone healing process $(10,13,14,27-30)$. Interestingly, previous studies have shown that the material-related inflammatory tissue response and the implant bed vascularization are (in-) directly connected. In specific, macrophages and BMGCs, among other different cell types, express angiogenic molecules like the vascular endothelial growth factor (VEGF) or the heme oxygenase 1 (HO-1). These angiogenic molecules have additional effects on the regeneration process by positively influencing cells like osteoblasts $(29,31)$. Moreover, a higher material-induced inflammatory tissue response caused by BBSM is linked to a high and fast implant bed vascularization $(17,20,32)$. Based on these results, BBSMs are assumed to undergo a desired degradation pattern for directed bone regeneration following the concept of Guided Bone Regeneration (GBR), which means that the formation of bone takes place on the basis of a translocating bone substitute material outgoing from the defect barriers directed into the central defect regions (17). It has also been revealed that BBSMs induce tissue reactions that may support the bone regeneration process $(17,20,32)$. Thus, BBSMs have been shown to be favorable materials for bone tissue regeneration in different preclinical and clinical studies $(10,12,17,20,21,23,24,32-34)$.

However, different clinical cases such as fracture cavities, interspaces around a screw or cysts, necessitate the application of an injectable bone substitute (IBS) $(2,11,12,22,29,31,35$ 38). This material class provides different benefits such as a minimally-invasive application and an optimal filling capability of irregularly shaped defects up to the defect borders $(2,31)$. Most of the IBS are based on calcium phosphate-based granules and hydrophilic polymers such as collagen, hyaluronic acid (HY) or cellulose $(2,12,29,31,36,38)$. It has been shown that the addition of HY and methylcellulose to $\beta$-TCP granules results in an IBS which features an integration behavior by inducing a continuous cellular ingrowth from the periphery towards the core and increases the vascularization of the implantation bed $(29,37,38)$. In a previous study it was concluded that this integration pattern is in accordance to the process of Guided Bone Regeneration (GBR) (31). However, it is also known that the application of HY fragments of different molecular sizes, i.e., high and low molecular weight hyaluronan (HMWHY/LMWHY), leads to different, sometimes opposing regenerative properties (20). HMWHY exhibits antiinflammatory and immunosuppressive characteristics, whereas LMWHY stimulates proinflammatory tissue reactions (39). Interestingly, another publication by Sieger and Korzinskas et al. showed that the addition of different amounts of HMWHY did not affect the inflammation response to BBS but improved the material handling properties (20).

In contrast, the IBS Maxresorb ${ }^{\circledR}$ inject (botiss biomaterials $\mathrm{GmbH}$, Zossen, Germany) is composed of biphasic bone substitute granules with a mixture of $60 \%$ HA and $40 \% \beta$-TCP and a water-based gel that contains HA nanoparticles with a size of $15-50 \mathrm{~nm}$ (38). Due to the special material composition of this IBS, it is of certain interest to analyze the integration behavior and the material-related tissue reactions compared to similar materials such as the above-mentioned polymers. Thus, the present in vivo study using the subcutaneous implantation model in CD-1 mice over a period of 60 days, was conducted to examine its integration behavior and the related inflammatory tissue responses including the induction of BMGCs as well as the implant bed vascularization. Pure biphasic bone substitute granules of the same size were used as control in order to analyze the influence of the water-based gel in combination with the HA nanoparticles towards the tissue reaction. Established and previously published systematic histological, histopathological and histomorphometrical methods were used to put focus on comparability of the present study results and former examinations $(2,10,17,20,21,29,31,32)$.

\section{Materials and Methods}

Bone substitute materials. Maxresorb inject ${ }^{\circledR}$. Maxresorb inject ${ }^{\circledR}$ (Botiss biomaterials $\mathrm{GmbH}$, Zossen, Germany) is an injectable and moldable alloplastic bone substitute material composed of amorphous nano-sized HA dispersed in water, which serves as carrier for the embedded biphasic granules (38). These biphasic granules are manufactured according to the manufacturing process described for maxresorb (38). The carrier matrix is precipitated from an aqueous solution of calcium and orthophosphoric acid. The ratio of biphasic granules and carrier matrix is $16.5 \%$ to $83.5 \%$ in the final bone substitute material, leading to the character of a viscous paste.

Maxresorb $^{\circledR}$. Maxresorb ${ }^{\circledR}$ (Botiss biomaterials GmbH, Zossen, Germany) is an alloplastic bone substitute material imitating the natural bone architecture and morphology (38). The synthetic bone substitute consists of two homogenously distributed phases of $60 \%$ hydroxyapatite (HA) und $40 \% \beta$-tricalcium phosphate $(\beta$-TCP). The manufacturing process of maxresorb includes a controlled precipitation process of aqueous solutions of calcium and phosphate as well as subsequent cold isostatic pressing into mechanically stable objects (38). This process results in an interconnecting porous system with defined pore diameters ranging from 200 to $800 \mu \mathrm{m}$ as well as micropores of 1-10 $\mu \mathrm{m}$. Finally, the alloplastic bone substitute material is grinded and sieved to obtain appropriate granule sizes prior to packaging and gamma-sterilization. 
Scanning electron microscopy. To analyze the ultrastructure of the bone substitute materials, scanning electron microscopy (SEM) via an AMRAY 1810 T (Amray Inc., Bedford, MA, USA) was performed for both biomaterials at $20 \mathrm{kV}$. The biomaterials were gold sputtered on a sample holder prior to the SEM analysis.

Experimental design and conduct of the subcutaneous implantation model. The in vivo experiments were conducted following established and previously published standardized methods $(2,10$, $17,20,21,29,31,32)$. Briefly, the biomaterials were implanted subcutaneously in 40 female 5 -week-old CD-1 mice with an average weight of 28 grams that were obtained from Charles River (Charles River Laboratories, Wilmington, MA, USA) after the approval of the Local Ethical Committee. The animals were maintained for 1 week before use at the Animal Facility of the Institute of Pathology of the University Medical Center of the Johannes Gutenberg University Mainz. Animals were kept under standard conditions with regular mouse pellets, access to water ad libitum and an artificial light-dark cycle of $12 \mathrm{~h}$ each. Implantations were conducted with $\mathrm{n}=4$ animals for 5 observation time points: i.e. $3,10,15,30$ and 60 days post implantationem in accordance to the guidelines of the Committee on the Use of Live Animals in Teaching and Research of the State of RhinelandPalatinate. Fifteen animals with $n=3$ animals per study time point were used as controls, by undergoing an operation without material implantation. Animals were nourished and kept under standard and artificial conditions. The subcutaneous implantation included the insertion of $60 \mathrm{mg}$ of bone substitute materials into a preformed subcutaneous pocket within the rostral subscapular region after intraperitoneal anesthesia $[10 \mathrm{ml}$ of ketamine $(50 \mathrm{mg} / \mathrm{ml})$ with 1.6 $\mathrm{ml}$ of $2 \%$ xylazine] under sterile conditions. Afterwards, wound closure was performed with Prolene 6.0 (Ethicon, Somerville, NJ, USA). After the respective study time points, the experimental animals were sacrificed by an overdose of ketamine and xylazine (double amount of the above-mentioned anesthetics). Additionally, the euthanasia was confirmed via exsanguination.

Tissue preparation and histological workup. In accordance to previously described methods, the implanted biomaterial and the peri-implant tissue were extracted and fixated in $4 \%$ formalin for $24 \mathrm{~h}(2,10,17,20,21,29,31,32)$. Subsequently, each biopsy was cut in three segments, a left and a right margin as well as a central part and decalcified in 10\% Tris-buffered EDTA (Carl Roth, Karslruhe, Germany) at $37^{\circ} \mathrm{C}$ for 4 days. Afterwards, dehydration in a series of increasing alcohol concentrations finally followed by xylol was conducted. Furthermore, the explants were embedded in paraffin, cut with a rotation microtome (Leica, Wetzlar, Germany) in 3-5 $\mu \mathrm{m}$ thick slices and stained with hematoxylin and eosin (H\&E), Azan, Sirius red, Masson Goldner trichrome and tartrateresistant acid phosphatase (TRAP).

Histopathological analysis. The histological examination of the tissue reactions to the bone substitute materials were conducted based on an established protocol $(2,10,17,20,21,29,31,32)$. Briefly, the tissue sections were analyzed histologically with a conventional diagnostic microscope (Eclipse 80i, Nikon, Tokyo, Japan) in combination with a digital camera (DS-Fi1, Nikon, Tokyo, Japan) with a digital sight control unit (Nikon, Tokyo, Japan). The total implantation bed and the peri-implant tissue of each animal were analyzed with consideration of the following parameters: fibrosis, hemorrhage, necrosis, vascularization and the presence of neutrophils, lymphocytes, plasma cells, macrophages as well as TRAP-positive and -negative biomaterial-induced multinucleated giant cells (BMGCs).

Histomorphometry. Additional to the histological analysis, histomorphometrical measurements were performed to determine the number of TRAP-positive and -negative biomaterial-induced multinucleated giant cells (BMGCs), the vessel density and the percent vascularization as previously published. Therefore, scans of the respective slides were recorded with a specialized microscope system including a light microscope (Eclipse 80i, Nikon, Tokyo, Japan) and a connected digital camera (DS-Fi1, Nikon, Tokyo, Japan) as well as an automatic scanning table (Prior Scientific, Rockland, MA, USA) combined with a computer running the software NIS-Elements (version 4.0, Nikon, Tokyo, Japan). Finally, the total scans were consisting of 100 to 120 single images of the region of interest including the implantation bed and the periimplant tissue at a $100 \times$ magnification.

To determine the percent vascularization and the number of vessels, initially the total implant area was measured with the NISElements "annotations and measurements" tool. Moreover, the numbers and areas of blood vessels on each slide were measured by manual marking. Based on this data, the total number of vessels was related to one square millimeter of the implant bed (vessels $/ \mathrm{mm}^{2}$ ) and the percentage of blood vessels was calculated relating the area of vessels to the implant area.

Furthermore, both TRAP-negative and TRAP-positive biomaterial-induced multinucleated giant cells (BMGCs) were counted manually and their numbers were related to one square millimeter of the implant bed (BMGCs $\left./ \mathrm{mm}^{2}\right)$.

Statistical analysis. The histomorphometrical data were used for an analysis of variance (ANOVA), which allowed for comparison of the histomorphometrical data, using the GraphPad Prism 6.0c software (GraphPad Software Inc., La Jolla, CA, USA). Statistical differences were designated as significant if $p$-values were less than 0.05 ( $p \leq 0.05$ ), and highly significant if $p$-values were less than 0.01 $(p \leq 0.01)$ or less than $0.001(p \leq 0.001)$. Finally, the results were graphed as mean \pm standard deviations.

\section{Results}

Analysis of the material (ultra-) structure. SEM analysis showed that the IBS exhibited a material structure similar to a coherent mass without signs of any particular components such as the biphasic bone substitute granules (Figure 1A). Moreover, no signs of macroporosity were observable (Figure 1A) while single smaller pores were found in higher magnifications (Figure 1B). Contrary to that, the granules of the biphasic bone substitute granules presented a foam-like structure with an open-porosity including both macro- and micropores (Figure 1C and D).

Analysis of the in vivo tissue reactions. All animals of the three experimental groups survived without any sign of macroscopically detectable wound disorders. Moreover, no abnormalities have been observed in any of the study groups regarding animal food and water intake behavior. 
Tissue reactions to the IBS. Starting with day 3 after implantation, and up to the end of the observation period, the IBS was detectable within the implantation bed (Figure 2). At the earliest study time point, a visible division between an outer and the inner region of the implanted material was histologically observable (Figure 2A and B). Small granules were located within the outer implant and big bone substitute granules were found building up the inner region of the implanted paste-like material (Figure 2A). At this time point, mononuclear cells such as granulocytes and macrophages along with some single fibroblasts could be identified building a multilayer on the surface of the outer region, embedded within a loose fibrin network, while no cells had reached the inner core of the implanted IBS (Figure 2A and B).

At day 10 after implantation, the separation in the abovementioned outer and inner region within the implantation bed of the IBS was still observable (Figure 2C). At this time point, a cell- and vessel-rich granulation tissue mainly including inflammatory cells, such as macrophages, lymphocytes and granulocytes and single biomaterial-induced multinucleated giant cells (BMGCs), was detectable, which penetrated the complete outer implant region (Figure 2D). In contrast to the latter, only a few mononuclear cells comprising mainly of macrophages, were detected within the intergranular interspaces of the bigger bone substitute granules positioned in the inner implant region of the IBS (Figure 2E).

After 15 days of implantation, the division of the implantation bed of the IBS into an outer region composed of the small granules and the inner region composed of the bigger bone substitute granules was still detectable (Figure $2 \mathrm{~F}$ ). Within the outer region, the afore-described cell- and vessel-rich granulation tissue with higher numbers of BMGCs was observed (Figure 2G). At this study time point, the ingrowth of mononuclear cells into the intergranular spaces within the inner implant bed region was increased, however there were no signs of an ingrowth of complex tissue (Figure 2H).

At day 30 after implantation, the tissue ingrowth towards the central region of the implantation bed continued (Figure 2I). The cell- and vessel-rich granulation tissue that included mainly macrophages, lymphocytes and fibroblasts remained within the interspaces of the small bone substitute granules in the outer region of the IBS implant bed (Figure 2J). At this time point the number of the BMGCs cells within the outer region of the implant bed had again increased compared to the previous time point (Figure 2J). At this study time point the big bone substitute granules within the central regions of the IBS implantation bed were also embedded within a cellrich and well vascularized connective tissue (Figure $2 \mathrm{~K}$ ). The same cell types that were found within the outer implant bed region were detected within the central regions at this time point, i.e., macrophages, lymphocytes, fibroblasts and BMGCs (Figure 2K).
At day 60 after implantation, the inner and outer regions of the implant bed remained divided (Figure 2L). At this study time point, a cell- and vessel-rich granulation tissue was observable within both implant bed regions. A Low number of BMGCs was associated with the smaller granules within the outer implant bed regions (Figure 2M). In contrast, higher numbers of BMGCs were found associated with the big bone substitute granules within the inner implant bed regions (Figure 2N).

Tissue reaction to the BBSM. Starting with day 3 after implantation, the bone substitute granules were embedded within a loose network of fibrin fibers (Figure 3A and B). A layer of mononuclear cells was observed over the granule surfaces even within the periphery of the implant beds, which could mainly be identified as granulocytes and macrophages (Figure 3A and B).

Beginning on day 10 after implantation, a noticeable connective tissue influx that included a moderate number of blood vessels, was observed up to the central regions of the implantation beds of the bone substitute. This was associated with the occurrence of macrophages and BMGCs at the material-tissue-interfaces (Figure 3C and D). At day 15 after implantation, more BMGCs were observed at the granule surface and within the intergranular spaces that were still filled with a cell- and vessel-rich connective tissue (Figure $3 \mathrm{E}$ and F). At day 30, a relatively large number of BMGCs and some mononuclear cells remained and could be observed at the granule surfaces, neighbored to the intergranular celland vessel-rich connective tissue (Figure $3 \mathrm{G}$ and $\mathrm{H}$ ). 60 days after implantation, comparable numbers of BMGCs were found at the material surfaces in combination with macrophages (Figure 3I and J). It was also observed at this study time point that the intergranular connective tissue was rich of cells and blood vessels (Figure 2E).

Tissue reaction to the control group. The control group implantation bed showed a continuously mild vascularization and within the first 15 days some granulocytes and macrophages were found (data not shown). No multinucleated giant cells were observed in this group at any study time point.

Histomorphometrical analysis of the vascularization. The histomorphometrical analysis of the control group showed a continuously mild vessel density and a relatively low percentual vascularization throughout the complete study period (Figure $4 \mathrm{~A}$ and $\mathrm{B})$. At day 3 after implantation, a mild vascularization was detected in the IBS group, while no vessels could be found within the implantation bed of the pure BBSM (Figure 4A and B). The vessel density of the IBS and also of the pure BBSM increased significantly $(p<0.001)$ between day 3 and day 10 after implantation (Figure 4A). Vessel numbers in both study groups were comparable to each other and significantly higher 


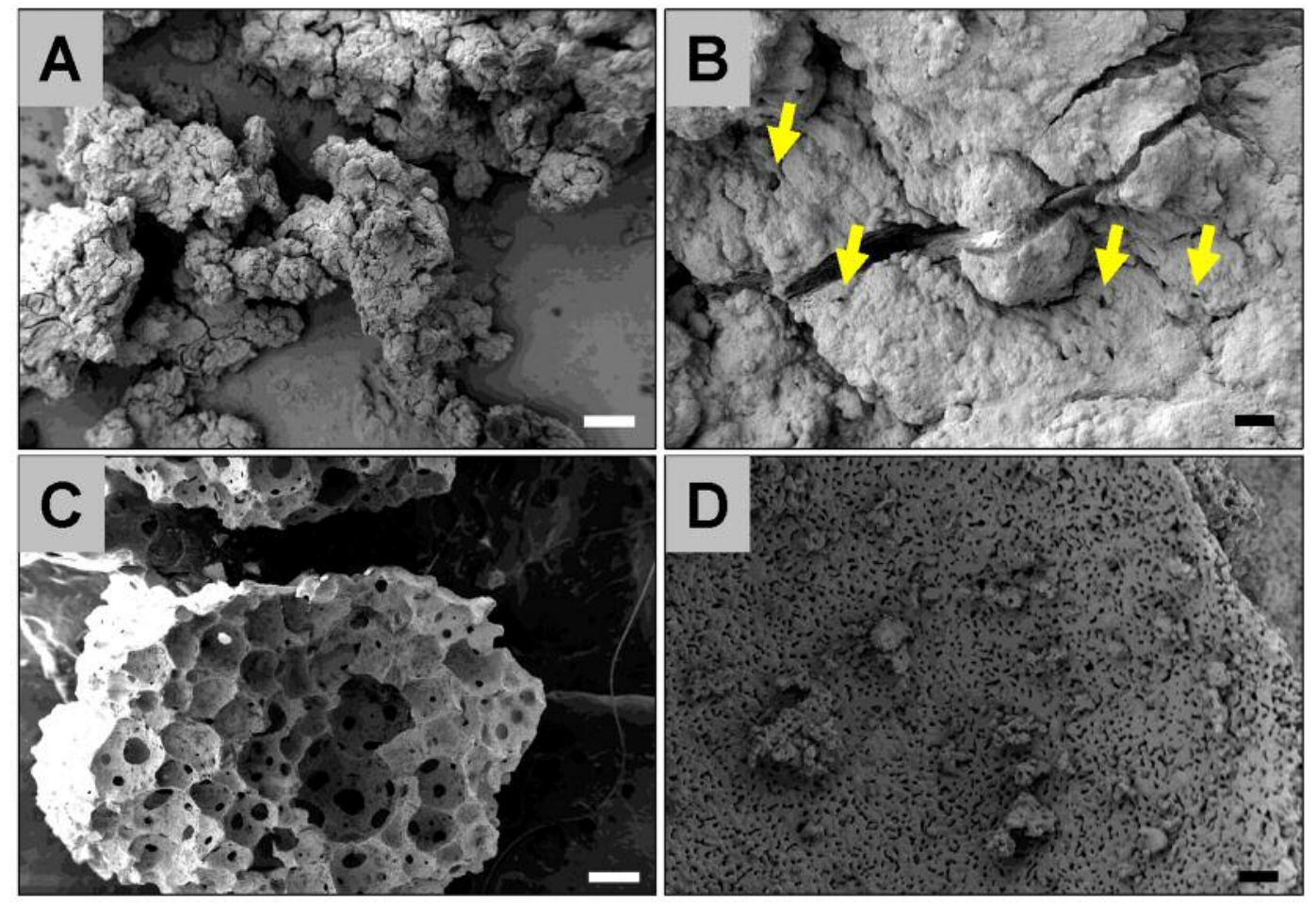

Figure 1. SEM-images of the two bone substitute materials. (A) and (B) show the injectable bone substitute, while $(C)$ and $(D)$ show representative images of the biphasic bone substitute granules. Micropores of the injectable bone substitute are indicated by the yellow arrows in $B$ (A and $C$ : $200 \times$ magnification, scale bars $=100 \mu \mathrm{m}, B$ and D: $1000 \times$ magnification, scale bars $=1 \mu \mathrm{m})$.

( $p<0.001$ and $p<0.01)$ compared to the values in the control group (Figure 4A). At day 15 and 30 after implantation, the vessel numbers in both material groups remained similar and significantly higher $(p<0.001$ and $p<0.01)$ than in the control group (Figure 4A). Furthermore, the vessel numbers reduced in both groups at 60 days after implantation, but this reduction was only significant in the pure BBSM group $(p<0.01)$ (Figure 4A). Interestingly, no differences in vessel numbers was found between each material group and the control group at this latest study time point (Figure 4A).

The histomorphometrical measurements for the percent of vascularization showed comparably low values at day 3 after implantation in all study groups, while no vascularization was found in the pure BBSM group (Figure 4B). An increase in the percentage of vascularization was found in both material groups at day 10 after implantation, but this increase was only significant $(p<0.001)$ in the pure BBSM group (Figure 4B). Moreover, the values in the BBSM group were also significantly higher $(p<0.001$ and $p<0.05)$ compared to that in the IBS and the control groups (Figure 4B). between days 15 to 60 after implantation, the values in the BBSM group were significantly higher $(p<0.001)$ compared to the values in the IBS and the control group (Figure 4B). Furthermore, no significant differences were found between the values in the
IBS group and the control group in this observation period (Figure 4B). A significant increase $(p<0.01)$ in the percentage of vascularization was solely found in the control group between day 30 and day 60 after implantation (Figure 4B).

Histomorphmetrical analysis of the BMGC induction. The histomorphometrical analysis of the BMGCs showed comparable numbers were found in both material groups at day 10 after implantation, which were significantly higher $(p<0.001$ and $p<0.05$ ) compared to 3 days after implantation (Figure 5A). However, the BMGC numbers in the IBS group tended to be higher compared the pure BBSM group (Figure 5A). At day 15 and day 30 after implantation, the BMGC numbers in the IBS were significantly higher $(p<0.001)$ compared to the values in the BBSM group (Figure 5A). At day 60 after implantation, the BMGC numbers in both material groups were on a comparable level, as a significant decrease $(p<0.01)$ was detected in the IBS group at this time point (Figure 5A).

Furthermore, the measurement of the TRAP-positive BMGC subpopulations showed comparable values of TRAPpositive BMGCs were found in both material groups at day 10 after implantation, but only a significant increase $(p<0.01)$ was found in the IBS group, whose values tended to be higher than the pure BBSM group (Figure 5B). At day 


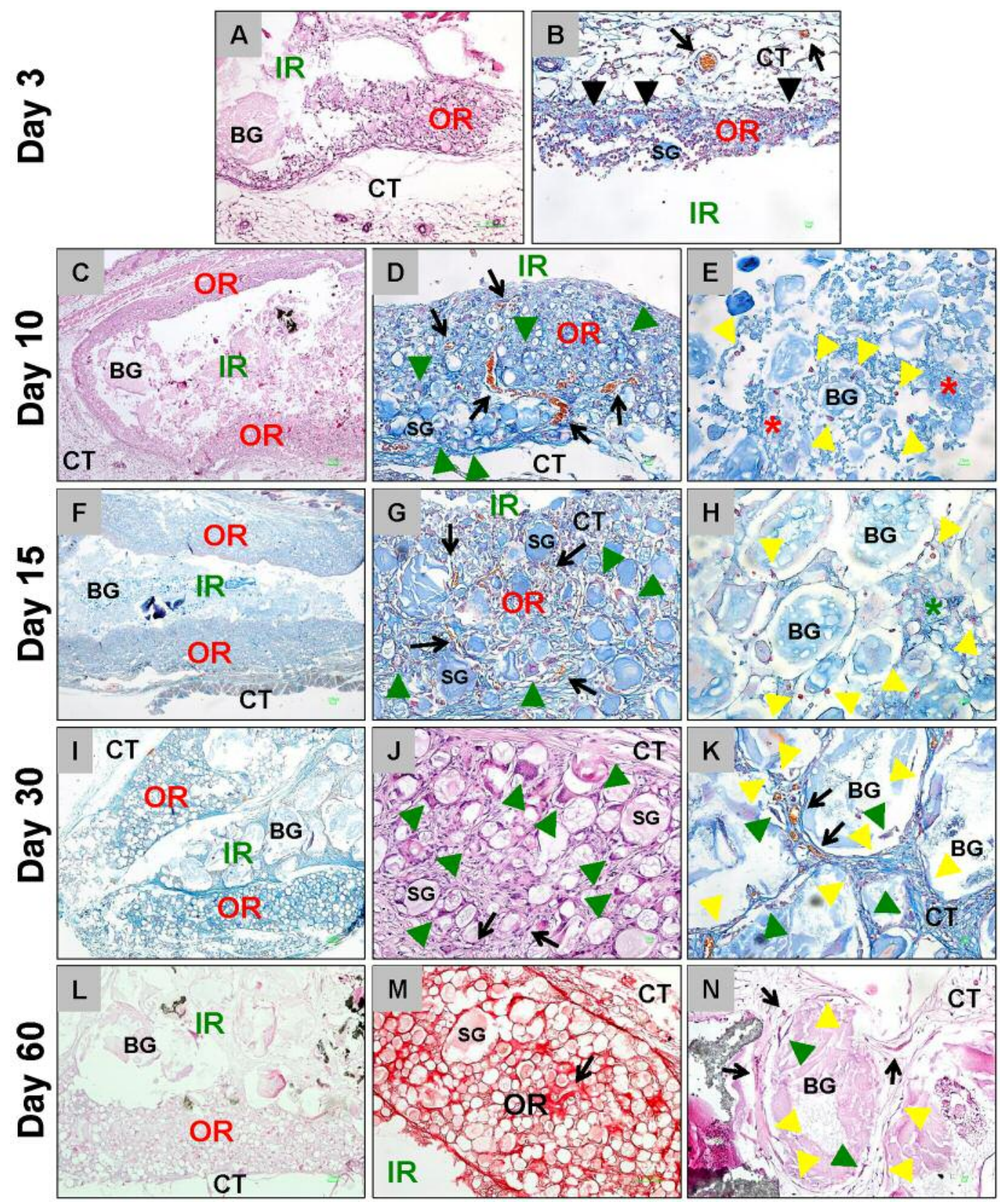

Figure 2. Representative images of the integration behavior and the tissue reactions of the injectable bone substitute material at day 3 (A and $B)$, day $10(\mathrm{C}-\mathrm{E})$, day $15(\mathrm{~F}-\mathrm{H})$, day $30(\mathrm{I}-\mathrm{K})$ and day $60(\mathrm{~L}-\mathrm{N})$ after implantation within the subcutaneous connective tissue $(\mathrm{CT})$. The implantation beds were distinguishable into an outer implant bed region (OR) including small bone substitute granules (SG) and an inner implant bed region (IR) composed of larger bone substitute granules. Black arrowheads=monocytes; black arrows=blood vessels; green arrowheads=multinucleated giant cells; yellow arrowheads=mononuclear cells; red asterisks=fibrin-like matrix; A, C, F; I and L=HE- or Azan-stainings, 40x magnifications, scale bars $=100 \mu \mathrm{m} ; \mathrm{B}, \mathrm{D}, \mathrm{E}, \mathrm{G}, \mathrm{H}, \mathrm{J}, \mathrm{K}, \mathrm{M}$ and $\mathrm{N}=\mathrm{HE}$-, Azan- or Sirius red stainings, 200x magnifications, scale bars=10 $\mu \mathrm{m}$.

15 and day 30 after implantation, the numbers of TRAPpositive BMGCs were significantly higher $(p<0.05$ and $p<0.001)$ in the group of the IBS, while comparable numbers were found at day 60 after implantation that correlated with a significant decrease $(p<0.05)$ in the IBS group (Figure 5B).
The histomorphometrical measurements of the TRAPnegative BMGCs showed that their numbers were comparably high in both material groups at day 10 after implantation, these values were significantly higher $\left(\bullet^{\bullet} p<0.001\right.$ and $\left.\bullet p<0.05\right)$ compared to day 3 after implantation (Figure 5C). At day 15 


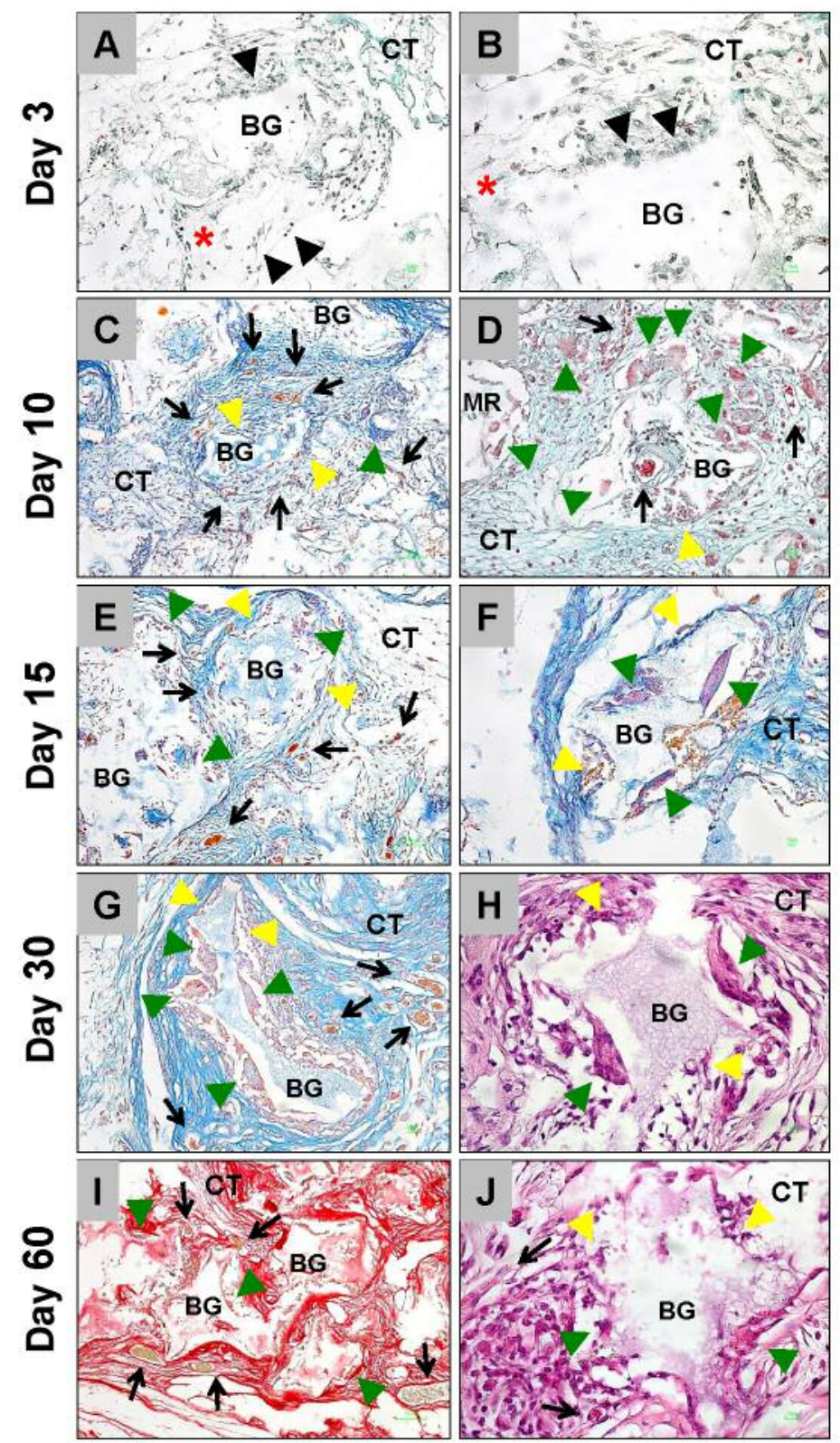

Figure 3. Representative images of the integration behavior and the tissue reactions of the biphasic bone substitute material at day 3 (A and B), day $10(C$ and $D)$, day 15 ( $E$ and $F)$, day $30(G$ and $H)$ and day 60 ( $I$ and $J)$ after implantation within the subcutaneous connective tissue $(C T)$. Black arrowheads=monocytes; red asterisks=fibrin-like matrix; black arrows=blood vessels; green arrowheads=multinucleated giant cells; yellow arrowheads=mononuclear cells; A, C, E, G and I=Masson Goldner-, Azan- and Sirius red-stainings, 100× magnifications, scale bars=20 $\mu$ m; B, D, F, $H$ and J=Masson Goldner, Movat Pentachrome-, Azan- and HE-stainings, 200x magnifications, scale bars=10 $\mu \mathrm{m}$.

and day 30 after implantation the numbers of TRAP-negative BMGCs were significantly higher $(* * p<0.01$ and $* * * p<0.001)$ in the IBS group (Figure 5C). Finally, comparable numbers were found in both groups at day 60 after implantation associated with a significant decrease $\left(\bullet^{\bullet} p<0.01\right)$ of the TRAPnegative BMGCs in the IBS group compared to day 30 after implantation (Figure 5C).

\section{Discussion}

In a previous in vivo study, it was shown that an IBS based on $\beta$-TCP granules, methylcellulose and HY produced an integration behavior characterized by a prolonged and continuous cellular ingrowth from the periphery towards the implant bed center, which was assumed to be in accordance 
A

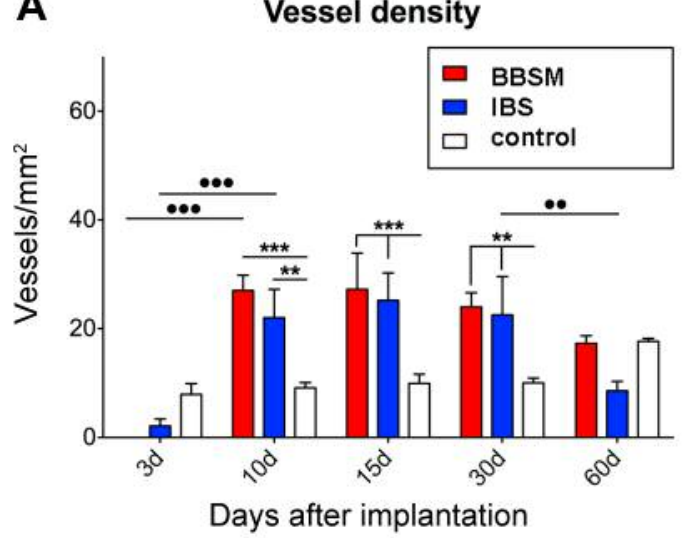

B

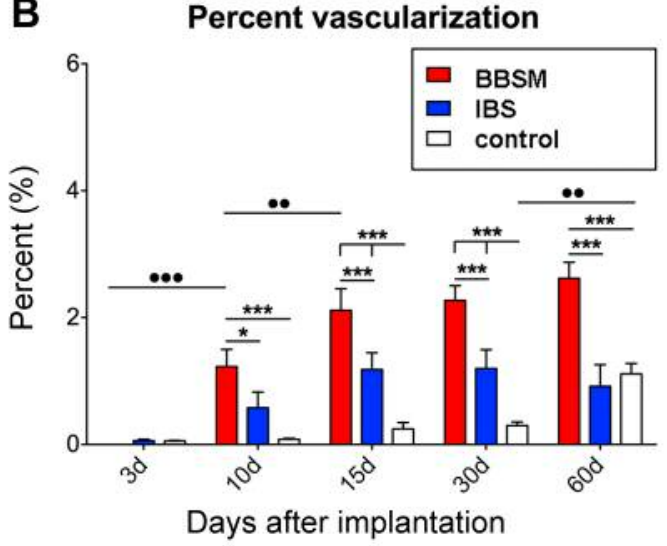

Figure 4. Histomorphometrical analysis of (A) the vessel density and $(B)$ the percent vascularization of the three study groups.

to the process of guided bone regeneration (GBR) (30). This process directs the growth of newly formed bone on basis of a scaffold structure, like that of the analyzed bone substitute material. Moreover, it has been shown that this IBS induced an increased implant bed vascularization, apparently based on its induction of a foreign body reaction including high numbers of BMGCs (29). Finally, its clinical efficiency in context of the augmentation of alveolar bone has also been proven (31).

In contrast, the IBS analyzed in the present study is composed of biphasic bone substitute granules with a mixture of $60 \%$ HA and $40 \% \beta$-TCP and a water-based gel combined with HA nanoparticles. Due to the lack of a hydrophilic polymer, it is of scientific interest to analyze the tissue reaction to this IBS with special consideration towards its integrational behavior. For this purpose, a previously used implantation model within the subcutaneous connective tissue in mice was used to mimic the material-tissueinteractions. Moreover, established and previously published systematic histopathological and histomorphometrical methods were used with the view of comparability between the study results with that of other bone substitute materials $(2,10,17,20,21,29,31,32)$.

The results showed that the implantation bed of the IBS could be divided into an outer and inner region, present immediately after its implantation and remained up during the subsequent 60 days that were analyzed in this study. Interestingly, the smaller granules were located within the outer implant region, building a layer around the inner implantation bed, where the bigger granules have been found. This material arrangement built a bulk-like structure, which inhibited a fast tissue ingrowth into the central regions of the implanted IBS. Up to day 30 after implantation, the ingrowing cells mainly interacted with the smaller bone substitute granules that seemed to prevent the ingrowth of complex tissue into the central regions. After this time point and up to day 60 after implantation, the bigger granules within the central implant regions were also integrated into connective tissue. In contrast, the granules of the pure BBSM were integrated into connective tissue starting from day 10 after implantation. Thus, the analyzed IBS allowed for a directed cell and tissue ingrowth that is comparable to the preclinical data reported for the afore-mentioned IBS based on $\beta$-TCP combined with a hydrogel of hyaluronic acid and methylcellulose within subcutaneous and bone tissue (2).

Moreover, the successful application of the analyzed IBS was also proven in a clinical study that showed it contributed to sufficient alveolar bone regeneration within extraction sockets (31). Altogether, the integration behavior of the analyzed IBS seems to be in accordance with the process of guided bone tissue regeneration. The IBS might support the directed ingrowth of osteoblasts migrating from the native bone tissue neighbored to the defect site. In this context, it has already been shown that the biomaterial affords predictable and stable clinical performance (40).

Interestingly, both the histological and the histomorphometrical results showed that a higher cell or tissue ingrowth, combined with higher numbers of BMGCs and blood vessels, were found associated to the smaller bone substitute granules within the outer implant bed region, beginning from day 10 up to day 60 after implantation. In contrast, the bigger granules within the inner core did not induce comparable numbers of BMGCs and additionally had a lower vascularization. This tissue reaction to the smaller granules led to significantly higher number of BMGCs as well as both their TRAP-positive and TRAP-negative subforms between day 10 and 30 after implantation in the IBS group compared to the other groups. In contrast, the numbers of BMGCs and their subpopulations were at a comparable level in both study groups at day 60 after implantation. Additionally, the measurements 
showed that the numbers of vessels were comparable in both study groups through the whole study period, while the percentage of vascularization was significantly higher in the group of the pure bone substitute granules compared to the IBS group throughout the whole observation period.

These observations show that the smaller granules within the outer region of the IBS induced a higher level of the material-associated foreign body response, which might on the one hand be based on the coherence of the smaller granules due to the added water-based gel. Thus, this coherence could have been led to a formation of a large material complex that was recognized as a big foreign body. In this context, the occurrence of such a big foreign body could have induced the observed high numbers of BMGCs.

However, it has already been reported that smaller sized bone substitute granules can induce a higher inflammatory tissue response $(13,17,28,29,41)$. This assumption also correlates with the higher intergranular vascularization, even within the outer implant bed region, as it was shown that smaller biphasic bone substitute granules support a fast and high vascularization process (29). Moreover, it has been shown in a previous in vivo publication that included six $\beta$ TCP-based bone substitute materials, that small granules induced the highest numbers of BMGCs and also correlated to a high vascularization of the implantation beds (29). Additionally, it has been shown in this study that the BMGCs are potent sources of the vascular endothelial growth factor (VEGF) and that the BMGC numbers correlated with the vascularization rates. Thus, the observations within the outer implant region of the analyzed IBS are in line with the previously reported results.

On the other hand, the low vascularization within the central implant regions led to an overall low vessel number of the implantation bed of the IBS that was comparable to the values in the BBSM group representing the bigger bone substitute granules. However, it is surprising that these bigger granules induced a higher percentage vascularization, which means that the diameter of the vessels was lower in the IBS group, while they induced lower BMGC numbers including lower TRAP-positive subforms of the multinucleated cells. Thus, it can be concluded that the bigger granules of the control group and also the bigger granules within the central implant bed regions of the IBS induced a lower so-called bioactivity while they supported an increase of the vessel diameters. The so-called intergranular gaps that are higher in case of bigger sized granules have also been discussed to be an important factor of the integration of a bone substitute (38, 42). Beside physicochemical material factors such as macroand microporosity or the composition of a synthetic bone substitute, the granule size and the resulting size of the intergranular gaps have been suspected to trigger a combination of a high surface area mediating resorption and the blood vessel ingrowth (42). Even the presented results

\section{A Total amount of BMGCs}

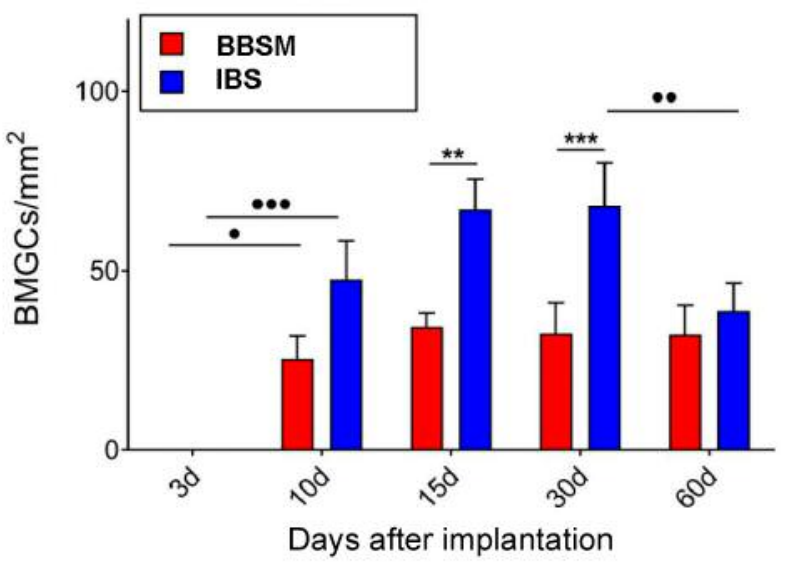

B Total amount of TRAP(+) BMGCs

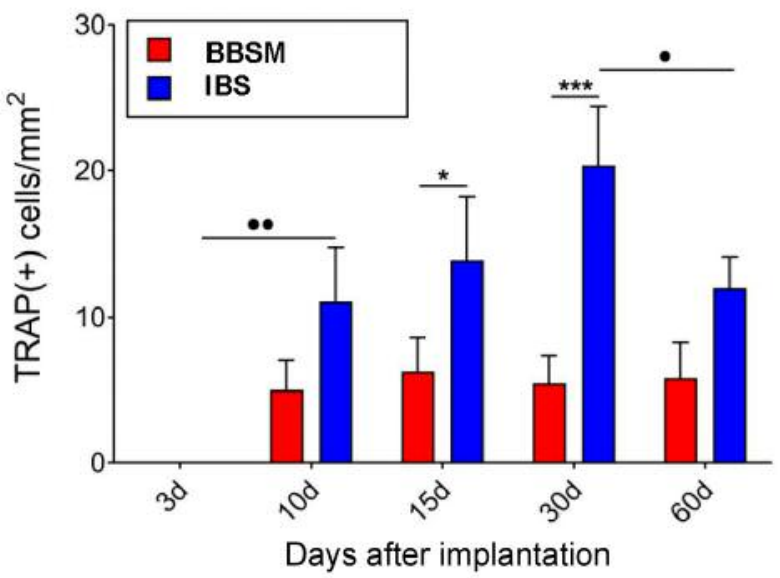

C Total amount of TRAP(-) BMGCs

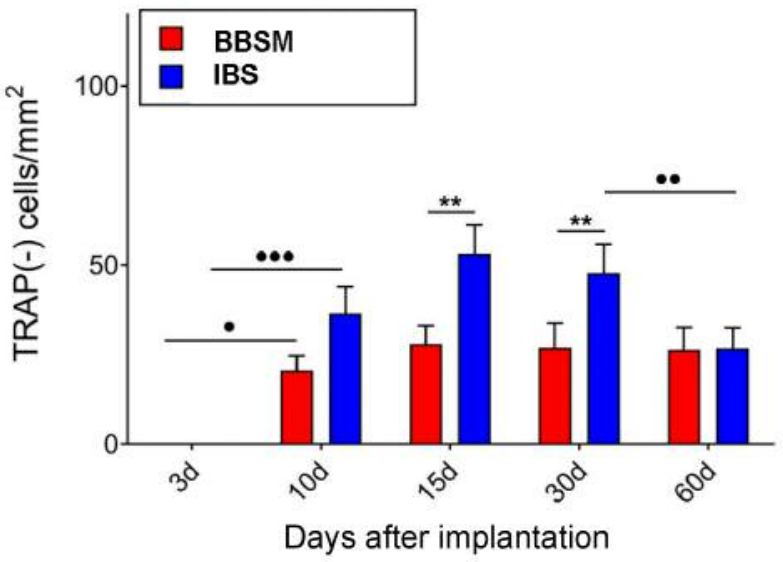

Figure 5. Histomorphometrical analysis of $(A)$ the total numbers of multinucleated giant cells as well as $(B)$ their TRAP-negative and $(C)$ TRAP-positive subpopulations. 
support this assumption. However, the combination of the higher vessel diameters with the lower numbers of BMGCs lead to the conclusion that a higher surface area, such as in case of the granules of the control group, does not have to lead to higher cell-based material resorption. For example, Busenlechner et al. showed that smaller granules of a bone substitute material are responsible for the osteoconduction process, which must be investigated in further studies (36). Altogether, the presented results lead to the conclusion that the overall tissue reactions to a bone substitute, including both the cellular resorption and the implant bed vascularization, are a result of the different physicochemical material characteristics as well as the "intergranular" microenvironment.

Moreover, the data shows that the composition of the analyzed IBS composed of biphasic bone substitute granules in aqueous solution, allows for a comparable integration pattern observed in other injectable materials, including natural polymers that are suspected to trigger bone regeneration $(2,12,29,31,36,38)$. Furthermore, the results revealed that the analyzed IBS acts as barrier-like structure, which prevent a premature soft tissue influx into the implantation bed central regions already at early time points (36) after implantation. Thus, the IBS should allow for an optimal integration behavior that is in accordance with the concept of Guided Bone Regeneration (GBR). Finally, the integration behavior of the pure biphasic bone substitute can be stated to be optimal for supporting bone regeneration as the material supports the implant bed vascularization by vessel maturation.

\section{Conclusion}

The present study analyzed the tissue reaction of an IBS in comparison to biphasic bone substitute granules within a subcutaneous tissue model in mice up to 60 days post implantationem. The results of the study have focused on analyzing the integration and degradation as a basis for its clinical application in humans. The results of the present study demonstrate that the IBS is able to build a barrier-like structure, which is able to control the soft tissue influx into the central regions of its implantation bed, not observed in the comparable bone substitute granules with the same chemical composition. This directed integration behavior is in accordance with the concept of Guided Bone Regeneration (GBR). Furthermore, the data indicate that the BMGCs can only influence angiogenesis but not the maturity of blood vessels. This important aspect of bone tissue regeneration is also influenced by factors such as the granule size and the following morphology of the intergranular gaps. Further studies have to examine the extent of inflammation and its exact affect in the perspective of macrophages and biomaterial-associated multinucleated giant cells and their involvement in the molecular basis of the bone tissue regeneration process.

\section{Conflicts of Interest}

The Authors declare no conflicts of interest.

\section{Authors' Contributions}

MB accomplished the study design, conducted the experiments and the analysis. MB wrote the first draft of the manuscript. OJ, RS, MG, RS, PR, AH and TK improved the final manuscript.

\section{Acknowledgements}

The Authors want to thank Samuel Udeabor, Charles James Kirkpatrick, Robert Sader, Jonas Lorenz and Shahram Ghanaati for their support of the study.

\section{References}

1 Peric Kacarevic Z, Kavehei F, Houshmand A, Franke J, Smeets R, Rimashevskiy D, Wenisch S, Schnettler R, Jung O and Barbeck M: Purification processes of xenogeneic bone substitutes and their impact on tissue reactions and regeneration. Int J Artif Organs 41(11): 789-800, 2018. PMID: 29707988. DOI: $10.1177 / 0391398818771530$

2 Barbeck M, Hoffmann C, Sader R, Peters F, Hubner WD, Kirkpatrick CJ and Ghanaati S: Injectable bone substitute based on beta-tcp combined with a hyaluronan-containing hydrogel contributes to regeneration of a critical bone size defect towards restitutio ad integrum. J Oral Implantol 42(2): 127-137, 2016. PMID: 26301338. DOI: 10.1563/aaid-joi-D-14-00203

3 Kolk A, Handschel J, Drescher W, Rothamel D, Kloss F, Blessmann M, Heiland M, Wolff KD and Smeets R: Current trends and future perspectives of bone substitute materials - from space holders to innovative biomaterials. J Craniomaxillofac Surg 40(8): 706-718, 2012. PMID: 22297272. DOI: 10.1016/j.jcms.2012.01.002

4 Nasr HF, Aichelmann-Reidy ME and Yukna RA: Bone and bone substitutes. Periodontol 2000 19: 74-86, 1999. PMID: 10321217. DOI: $10.1111 /$ j.1600-0757.1999.tb00148.x

5 Sheikh Z, Hamdan N, Ikeda Y, Grynpas M, Ganss B and Glogauer M: Natural graft tissues and synthetic biomaterials for periodontal and alveolar bone reconstructive applications: A review. Biomater Res 21: 9, 2017. PMID: 28593053. DOI: 10.1186/s40824-017-0095-5

6 Tawil G, Barbeck M, Unger R, Tawil P and Witte F: Sinus floor elevation using the lateral approach and window repositioning and a xenogeneic bone substitute as a grafting material: A histologic, histomorphometric, and radiographic analysis. Int $\mathrm{J}$ Oral Maxillofac Implants 33(5): 1089-1096, 2018. PMID: 29894551. DOI: $10.11607 /$ jomi.6226

7 Beaman FD, Bancroft LW, Peterson JJ and Kransdorf MJ: Bone graft materials and synthetic substitutes. Radiol Clin North Am 44(3): 451-461, 2006. PMID: 16644361. DOI: 10.1016/j.rcl. 2006.01.001

8 Hammerle $\mathrm{CH}$ and Karring T: Guided bone regeneration at oral implant sites. Periodontol 2000 17: 151-175, 1998. PMID: 10337322. DOI: 10.1111/j.1600-0757.1998.tb00132.x

9 Lee EJ, Kasper FK and Mikos AG: Biomaterials for tissue engineering. Ann Biomed Eng 42(2): 323-337, 2014. PMID: 23820768. DOI: 10.1007/s10439-013-0859-6 
10 Barbeck M, Dard M, Kokkinopoulou M, Markl J, Booms P, Sader RA, Kirkpatrick CJ and Ghanaati S: Small-sized granules of biphasic bone substitutes support fast implant bed vascularization. Biomatter 5: e1056943, 2015. PMID: 26083163 DOI: $10.1080 / 21592535.2015 .1056943$

11 Bongio M, van den Beucken JJ, Leeuwenburgh SC and Jansen JA: Preclinical evaluation of injectable bone substitute materials J Tissue Eng Regen Med 9(3): 191-209, 2015. PMID: 23135814. DOI: $10.1002 /$ term.1637

12 Zampelis V, Tagil M, Lidgren L, Isaksson H, Atroshi I and Wang JS: The effect of a biphasic injectable bone substitute on the interface strength in a rabbit knee prosthesis model. J Orthop Surg Res 8: 25, 2013. PMID: 23899023. DOI: 10.1186/1749-799X-8-25

13 Barbeck M, Udeabor SE, Lorenz J, Kubesch A, Choukroun J, Sader RA, Kirkpatrick CJ and Ghanaati S: Induction of multinucleated giant cells in response to small sized bovine bone substitute (bio-oss) results in an enhanced early implantation bed vascularization. Ann Maxillofac Surg 4(2): 150-157, 2014 PMID: 25593863. DOI: 10.4103/2231-0746.147106

14 Barbeck M, Udeabor S, Lorenz J, Schlee M, Holthaus MG, Raetscho N, Choukroun J, Sader R, Kirkpatrick CJ and Ghanaati S: High-temperature sintering of xenogeneic bone substitutes leads to increased multinucleated giant cell formation: In vivo and preliminary clinical results. J Oral Implantol 41(5): e212222, 2015. PMID: 25105868. DOI: 10.1563/aaid-joi-D-14-00168

15 Barbeck M, Booms P, Unger R, Hoffmann V, Sader R, Kirkpatrick CJ and Ghanaati S: Multinucleated giant cells in the implant bed of bone substitutes are foreign body giant cells-new insights into the material-mediated healing process. J Biomed Mater Res A 105(4): 1105-1111, 2017. PMID: 28093892. DOI: 10.1002/jbm.a.36006

16 Detsch R, Mayr H and Ziegler G: Formation of osteoclast-like cells on ha and tcp ceramics. Acta Biomater 4(1): 139-148, 2008. PMID: 17723325. DOI: 10.1016/j.actbio.2007.03.014

17 Ghanaati S, Barbeck M, Detsch R, Deisinger U, Hilbig U, Rausch V, Sader R, Unger RE, Ziegler G and Kirkpatrick CJ: The chemical composition of synthetic bone substitutes influences tissue reactions in vivo: Histological and histomorphometrical analysis of the cellular inflammatory response to hydroxyapatite, beta-tricalcium phosphate and biphasic calcium phosphate ceramics. Biomed Mater 7(1): 015005, 2012. PMID: 22287541. DOI: 10.1088/1748$6041 / 7 / 1 / 015005$

18 Lorenz J, Kubesch A, Korzinskas T, Barbeck M, Landes C, Sader RA, Kirkpatrick CJ and Ghanaati S: Trap-positive multinucleated giant cells are foreign body giant cells rather than osteoclasts: Results from a split-mouth study in humans. J Oral Implantol 41(6): e257-266, 2015. PMID: 25490579. DOI: 10.1563/aaid-joi-D-14-00273.

19 Lorenz J, Barbeck M, Sader RA, Kirkpatrick CJ, Russe P, Choukroun J and Ghanaati S: Foreign body giant cell-related encapsulation of a synthetic material three years after augmentation. J Oral Implantol 42(3): 273-277, 2016. PMID: 26824327. DOI: 10.1563/aaid-joi-D-15-00133

20 Sieger D, Korzinskas T, Jung O, Stojanovic S, Wenisch S, Smeets R, Gosau M, Schnettler R, Najman S and Barbeck M: The addition of high doses of hyaluronic acid to a biphasic bone substitute decreases the proinflammatory tissue response. Int J Mol Sci 20(8), 2019. PMID: 31013636. DOI: $10.3390 / \mathrm{ijms} 20081969$
21 Barbeck M, Unger RE, Booms P, Dohle E, Sader RA, Kirkpatrick CJ and Ghanaati S: Monocyte preseeding leads to an increased implant bed vascularization of biphasic calcium phosphate bone substitutes via vessel maturation. J Biomed Mater Res A 104(12): 2928-2935, 2016. PMID: 27419378. DOI: 10.1002/jbm.a.35834

22 Baroth S, Bourges X, Goyenvalle E, Aguado E and Daculsi G: Injectable biphasic calcium phosphate bioceramic: The hydros concept. Biomed Mater Eng 19(1): 71-76, 2009. PMID: 19458448. DOI: 10.3233/BME-2009-0565

23 Jelusic D, Zirk ML, Fienitz T, Plancak D, Puhar I and Rothamel D: Monophasic ss-tcp vs. Biphasic ha/ss-tcp in two-stage sinus floor augmentation procedures - a prospective randomized clinical trial. Clin Oral Implants Res 28(10): e175-e183, 2017. PMID: 27683073. DOI: $10.1111 / \mathrm{clr} .12983$

24 La Monaca G, Iezzi G, Cristalli MP, Pranno N, Sfasciotti GL and Vozza I: Comparative histological and histomorphometric results of six biomaterials used in two-stage maxillary sinus augmentation model after 6-month healing. Biomed Res Int 2018: 9430989, 2018. PMID: 30050947. DOI: $10.1155 / 2018 / 9430989$

25 Smeets R, Kolk A, Gerressen M, Driemel O, Maciejewski O, Hermanns-Sachweh B, Riediger D and Stein JM: A new biphasic osteoinductive calcium composite material with a negative zeta potential for bone augmentation. Head Face Med 5: 13, 2009. PMID: 19523239. DOI: 10.1186/1746-160X-5-13

26 Stein JM, Fickl S, Yekta SS, Hoischen U, Ocklenburg C and Smeets R: Clinical evaluation of a biphasic calcium composite grafting material in the treatment of human periodontal intrabony defects: A 12-month randomized controlled clinical trial. J Periodontol 80(11): 1774-1782, 2009. PMID: 19905932. DOI: 10.1902/jop.2009.090229

27 Barbeck M, Najman S, Stojanovic S, Mitic Z, Zivkovic JM, Choukroun J, Kovacevic P, Sader R, Kirkpatrick CJ and Ghanaati $\mathrm{S}$ : Addition of blood to a phycogenic bone substitute leads to increased in vivo vascularization. Biomed Mater 10(5): 055007, 2015. PMID: 26359820. DOI: 10.1088/1748-6041/10/5/055007

28 Ghanaati S, Barbeck M, Orth C, Willershausen I, Thimm BW, Hoffmann C, Rasic A, Sader RA, Unger RE, Peters F and Kirkpatrick CJ: Influence of beta-tricalcium phosphate granule size and morphology on tissue reaction in vivo. Acta Biomater 6(12): 4476-4487, 2010. PMID: 20624495. DOI: 10.1016/ j.actbio.2010.07.006

29 Ghanaati S, Barbeck M, Hilbig U, Hoffmann C, Unger RE, Sader RA, Peters F and Kirkpatrick CJ: An injectable bone substitute composed of beta-tricalcium phosphate granules, methylcellulose and hyaluronic acid inhibits connective tissue influx into its implantation bed in vivo. Acta Biomater 7(11): 4018-4028, 2011. PMID: 21784183. DOI: 10.1016/j.actbio.2011.07.003

30 Spiller KL, Anfang RR, Spiller KJ, Ng J, Nakazawa KR, Daulton JW and Vunjak-Novakovic G: The role of macrophage phenotype in vascularization of tissue engineering scaffolds. Biomaterials 35(15): 4477-4488, 2014. PMID: 24589361. DOI: 10.1016/j.biomaterials.2014.02.012

31 Lorenz J, Barbeck M, Kirkpatrick CJ, Sader R, Lerner H and Ghanaati S: Injectable bone substitute material on the basis of beta-tcp and hyaluronan achieves complete bone regeneration while undergoing nearly complete degradation. Int $\mathbf{J}$ Oral Maxillofac Implants 33(3): 636-644, 2018. PMID: 29543928. DOI: $10.11607 /$ jomi.6026 
32 Barbeck M, Serra T, Booms P, Stojanovic S, Najman S, Engel E, Sader R, Kirkpatrick CJ, Navarro M and Ghanaati S: Analysis of the in vitro degradation and the in vivo tissue response to bi-layered 3d-printed scaffolds combining pla and biphasic pla/bioglass components - guidance of the inflammatory response as basis for osteochondral regeneration. Bioact Mater 2(4): 208-223, 2017. PMID: 29744431. DOI: 10.1016/j.bioactmat.2017.06.001

33 Cordaro L, Bosshardt DD, Palattella P, Rao W, Serino G and Chiapasco M: Maxillary sinus grafting with bio-oss or straumann bone ceramic: Histomorphometric results from a randomized controlled multicenter clinical trial. Clin Oral Implants Res 19(8): 796-803, 2008. PMID: 18705811. DOI: 10.1111/j.1600-0501.2008.01565.x

34 LeGeros RZ, Lin S, Rohanizadeh R, Mijares D and LeGeros JP: Biphasic calcium phosphate bioceramics: Preparation, properties and applications. J Mater Sci Mater Med 14(3): 201-209, 2003. PMID: 15348465. DOI: 10.1023/a:1022872421333

35 Bojar W, Kucharska M, Bubak G, Ciach T, Koperski L, Jastrzebski Z, Gruber BM, Krzyszton-Russjan J, Marczewska J, Anuszewska EL, Drozd E and Brynk T: Formation and preclinical evaluation of a new alloplastic injectable bone substitute material. Acta Bioeng Biomech 14(1): 39-44, 2012. PMID: 22742431.

36 Busenlechner D, Tangl S, Fitzl C, Bernhart T, Gruber R and Watzek G: Paste-like inorganic bone matrix: Preclinical testing of a prototype preparation in the porcine calvaria. Clin Oral Implants Res 20(10): 1099-1104, 2009. PMID: 19681965. DOI: 10.1111/j.1600-0501.2009.01743.x

37 Krause M, Oheim R, Catala-Lehnen P, Pestka JM, Hoffmann C, Huebner W, Peters F, Barvencik F and Amling M: Metaphyseal bone formation induced by a new injectable beta-tcp-based bone substitute: A controlled study in rabbits. J Biomater Appl 28(6): 859-868, 2014. PMID: 23669497. DOI: 10.1177/08853 28213484816
38 Weiss P, Gauthier O, Bouler JM, Grimandi G and Daculsi G: Injectable bone substitute using a hydrophilic polymer. Bone 25(2 Suppl): 67s-70s, 1999. PMID: 10458279. DOI: 10.1016/s8756-3282(99)00146-5

39 Ferreira AM, Gentile P, Chiono V and Ciardelli G: Collagen for bone tissue regeneration. Acta Biomater 8(9): 3191-3200, 2012. PMID: 27762547. DOI: 10.1021/acsami.6b09241

40 Papanchev G, Georgiev T, Peev S, Arnautska H, Zgurova N, Borisova-Papancheva $\mathrm{T}$ and Dzhongova E: Comparison of the rates of bone regeneration in sinus lift grafting with a calciumphosphate paste between the 6th and the 9th month- a clinical case. Scr Sci Med Dent 1: 43-51, 2015. DOI: 10.14748/.v1i1.635

41 Soehnlein O, Wantha S, Simsekyilmaz S, Doring Y, Megens RT, Mause SF, Drechsler M, Smeets R, Weinandy S, Schreiber F, Gries T, Jockenhoevel S, Moller M, Vijayan S, van Zandvoort MA, Agerberth B, Pham CT, Gallo RL, Hackeng TM, Liehn EA, Zernecke A, Klee D and Weber C: Neutrophil-derived cathelicidin protects from neointimal hyperplasia. Sci Transl Med 3(103): 103ra198, 2011. PMID: 21974936. DOI: 10.1126/scitranslmed.3002531

42 Bohner M and Baumgart F: Theoretical model to determine the effects of geometrical factors on the resorption of calcium phosphate bone substitutes. Biomaterials 25(17): 3569-3582, 2004. PMID: 15020131. DOI: 10.1016/j.biomaterials.2003.10.032
Received November 1, 2019

Revised November 18, 2019 Accepted November 25, 2019 